\title{
Developing and Evaluating the Effectiveness of the Behavioral-Cognitive-Metacognitive Intervention on the Severity of Obsessive- Compulsive Disorder's Symptoms
}

\author{
Masoud Nikfarjam1, Mehdi Rabiei2² ${ }^{*}$ Vahid Donyavi ${ }^{3}$, Amir Mohsen Rahnejat ${ }^{4}$ \\ ${ }^{1}$ Medical Plants Research Center, Shahrekord University of Medical Sciences, Shahrekord, Iran \\ ${ }^{2}$ Department of Clinical Psychology, Baqiyatallah University of Medical Sciences, Tehran, Iran \\ ${ }^{3}$ Department of Psychiatry, AJA University of Medical Science, Tehran, Iran \\ ${ }^{4}$ Department of Clinical Psychology, AJA University of Medical Science, Tehran, Iran \\ Email: ${ }^{*}$ Rabiei_Psychology @yahoo.com
}

Received 1 June 2015; accepted 6 July 2015; published 9 July 2015

Copyright (C) 2015 by authors and Scientific Research Publishing Inc.

This work is licensed under the Creative Commons Attribution International License (CC BY).

http://creativecommons.org/licenses/by/4.0/

\section{(c) (i) Open Access}

\begin{abstract}
Obsessive-compulsive disorder is a disorder which is resistant to the existing treatments and to compensate this defect, it is necessary to design and search for the new treatments. This study aims to develop and evaluate the effectiveness of the behavioral-cognitive-metacognitive intervention on the symptoms of obsessive-compulsive disorder. In order to achieve objectives of the study, after developing the behavioral-cognitive-metacognitive intervention, it was evaluated in a single-subject procedure. OCI-R scores at baseline were obtained by following the treatment on 3 individuals. The study was a single-subject research and the data were analyzed by drawing the graph. Graph drawing results showed that the behavioral-cognitive-metacognitive intervention reduced the symptoms of obsessive-compulsive disorder (OCD), and reduction of OCD symptoms was also clinically significant. As the intervention of the present study is multi-dimensional and takes into account all the three behavioral, cognitive and metacognitive aspects and considers them interdependent and not apart or contradictory, it is considered as a new intervention.
\end{abstract}

\section{Keywords}

Treatment, Obsessive-Compulsive Disorder (OCD), Behavior, Cognition, Metacognition

\footnotetext{
${ }^{*}$ Corresponding author.
} 


\section{Introduction}

Obsessive-Compulsive Disorder (OCD) is a disabling anxiety disorder and its main characteristic is repetitive and severe obsessions and compulsions which bring considerable pain for sufferers. The obsessions or compulsions can cause time wasting and significant disturbance in normal life, occupational function, social activities and individual's relations [1]. The concept of "obsession" inducts surrounding the mind with unwelcome thoughts and the concept of "compulsion" inducts thought and action constraint, and it is not possible to understand these concepts without linking them to one's "ego" who feels constraint in free expression of thought, imagination and his own action. The constraint which is only abated by the action of an illness and temporary tranquility is obtained only by repetition and compulsion [2]. OCD is a disorder which is characterized by unwanted thoughts, images and impulses, or compulsive behaviors. This disorder brings damages and negative consequences for individuals and families who affected by OCD. Approximately, 2.2 percent of people in the general population suffer from OCD which cause to severe damage in psychological and social functioning in the sufferers [3].

Recently, it has been suggested that obsessive-compulsive disorder along with several connected disorders can be categorized separately in an obsessive-compulsive category. Obsessive-compulsive category includes many psychiatric states, but the most important of them based on the study done by [4] and the revisions of DSM-5 are: obsessive-compulsive disorder, hoarding obsession, Body Dismorphic Disorder (BDD), trichotillomania and pathological symptoms of skin picking. The reason for classification of these disorders in the same class is that they are associated with each other in terms of the obvious cognitive mechanisms, features such as age of onset, clinical course and comorbidity, the assumptions of etiology, familial factors and response to the medical and behavioral treatments [1].

Among common treatments and models that are currently used to explain obsessive-compulsive disorders' class, Cognitive Behavioral Therapy (CBT) and newer treatments such as meta-cognitive therapy for OCD can be noted. However, each of these models has some limitations that are mentioned below. Cognitive-behavioral model is a successful model in explaining obsessive-compulsive disorders in which two dimensions of cognitive and behavioral are taken into consideration for explanation of these disorders [5].

Cognitive view is more concerned with content of thoughts, and information processing and metacognitive processes of disorders (e.g. positive metacognitive beliefs, meta-worry and metacognitive control strategies) are less taken into consideration for explanation. On the other hand, metacognitive model also focuses only on processing aspects of information, and the role of thoughts such as core beliefs, cognitive distortions, negative automatic thoughts, and behavioral aspect is less taken into consideration. In this model, it is believed that cognitive factor can be starting point of the problem, but it needs to have some interaction with metacognitive and behavioral factors to intensify the problem. In other words, these factors are interdependent and inseparable from each other and they don't act in isolation. To understand the developed model, it is explained step by step as follows:

In the behavioral-cognitive-metacognitive model, it is believed that at first negative cognitions come to the mind in which this phase is common in the mind and cognitive function of most people and it is a relatively normal phase, that is, the presence of negative cognitions (thoughts, impulses or images) doesn't mean the disorder. The results of some studies [6]-[10] also support this idea.

This question may be raised that if negative cognitions don't cause the disorder by themselves, so which factors cause to the disorder?

In the presented behavioral-cognitive-metacognitive model, the starting process, duration of OCD is explained as follows:

1) In this model, it is believed that our sight and attitude towards negative cognitions can result in cognitive distortion. For example, if we have negative attitude (negative metacognitive beliefs) towards negative cognitions of our mind, and consider them unnatural, after a while, we will have fear of them and consider them dangerous. Therefore, there is an interaction between cognitive and metacognitive factors.

2) Considering the negative cognitions dangerous, scary causes to meta-worry. Worry may occur to many people and doesn't cause any problem, but meta-worry is more serious and usually leads people to illnesses. In this model, it is believed that negative beliefs towards negative cognitions result in meta-worry and then people decide to get rid of these negative cognitions in any way [11]. In this phase, the individuals use thought control strategies or compulsive behaviors. 
3) In order to not be faced with pain and discomfort due to negative thoughts, images, memories, impulses and emotions, individuals may do the following behaviors:

a) Cognitive control strategies: all cognitive activities that aim to avoid the negative thoughts, images, memories and impulses are included in this category. In addition to the mechanisms that Freud and Anna Freud introduced, there are also some conscious strategies which are aimed at avoiding the negative thoughts, images, memories and impulses. Among these strategies are distracting, concentration on the thoughts, positive images, memories and impulses and positive assessment which may cause individual's temporary calmness, but in fact cause individuals to get away from accepting the realities of their existence.

b) Behavioral control strategies: in order to avoid being faced with negative thoughts, images, memories, impulses, emotions and behaviors, we do various actions and behaviors, because they are painful.

In the behavioral-cognitive-metacognitive intervention, the following considerations will be emphasized respectively:

1) It is trained to the patients that not to have negative attitude towards negative thoughts, images, impulses and beliefs, and not to bear any responsibility and have feeling of being guilty because of their existence, and also don't blame themselves for them, because these cognitions may come to every person's mind and their existence is not an indicative of the illness.

2) In addition, the patients are taught to identify their cognitive distortions and errors (e.g. absolute orientation, extreme accountability, etc.) and challenge them with cognitive and behavioral considerations.

3) It is trained to the patients that if they have negative attitude towards negative cognitions, little by little it causes to worry and consequently to meta-worry, that is to say they think that their mind works abnormally, and maybe think that they get mad and lose their control, and for this reason they try to get rid of these negative cognitions in any possible way.

4) It is said to the patients that in this phase they try to control their negative cognitions. Individuals use different strategies to control their negative cognitions such as repression, elimination, distraction, self-blame, and taking medicine. Patients should be instructed that in this phase any attempt to control thoughts usually gives inverse answer and result in failure.

5) Furthermore, patients are taught that using obsessive behaviors may cause to temporal calmness, but in the long run result in durability of mentioned vicious cycle, and for treatment, they are trained to avoid obsessive, avoidance and safety behaviors.

It should be mentioned that the above five stages has been stated in summary and each of them has its own techniques and special functions. From the above-mentioned stages, it can be understood that in the developed behavioral-cognitive-metacognitive intervention, all the three components of behavioral, cognitive and metacognitive have been carefully taken into consideration.

Thus, the purpose of the present study is to examine the effect of behavioral-cognitive-metacognitive intervention on the symptoms of OCD.

\section{Methods}

\subsection{Experimental Design}

The intervention of the present study has been developed based on the survey and clinical studies of the authors [6]-[8] [10]-[12] and it has theoretical and clinical background. All mentioned variables in the model of the present study have face and content validity and conform to the behavioral, cognitive and metacognitive models, that is to say there is no difference between the definition of the variables in the model of the present study and the definition presented by cognitive, behavioral and metacognitive experts. To evaluate the effectiveness of the intervention, single-subject research was used. A single case study which sometimes is called single-subject research or single-subject experiment is a research that involves intensive study on a limited number of subjects who are considered individually or as a single group. Patients received twelve individual weekly sessions of the Behavioral-Cognitive-Metacognitive Intervention of 45 - 60 min duration. The clinical study was approved by the (Committee for the protection of persons) on June 14th, 2013 in Isfahan, Iran.

\subsection{Participants}

OCD diagnosis was established using the structured clinical interview for DSM-5 diagnoses (DSM-5; American Psychiatric Association, 2013). The diagnoses were made by the first author. All participants met the criteria for 
diagnosis of OCD set by DSM-5. They were all willing to participate in our treatment study and their major problem was OCD.

Three patients were recruited (2 females), ages ranging from 15 to 50 years. Participants were married. Their socio-economic status was average or above average. Classification of socio-economic status was based on coding of the subjects income, education and job. Also, they all had some high school diploma and university education. None of the patients were currently taking psychotropic medication. The duration of their OCD ranged from 1 to 10 years.

\subsection{Data Reduction and Analysis}

The statistical population of the study includes all outpatients with obsessive-compulsive disorders in Isfahan (2013). Based on the DSM-IV-TR criteria and proposed reforms of DSM-5 [1], three outpatients who suffered from OCD were selected purposefully from counseling center of Foolad Mobarakeh in Isfahan, Iran. These patients were treated with behavioral-cognitive-metacognitive intervention by a single-subject method. The sampling method of the research was "Purposive sampling". The purpose of researcher is this sampling is to select those that are consistent with objectives of the research. The inclusion criteria of the study were having at least a high school education, no hospitalization, being from Isfahan, being Persian, being at the age range of 15 - 50, and satisfaction and cooperation of the subjects. Subjects who did not have the above-mentioned criteria were excluded from the study.

\subsection{Measurements}

1) The revised obsessive-compulsive inventory: Obsessive-Compulsive Inventory-Revised (OCI-R) [13]; is an 18-item scale which measures obsessive-compulsive symptoms (e.g. hoarding, washing, ordering, checking out, obsession and mental neutralizing symptoms). In general, the score range of the revised form of the questionnaire is from 0 to 72 in which higher scores indicate the intensity of symptoms. A good internal consistency ( $\alpha=0.80-0.88)$ and acceptable test-retest reliability $(r=0.67-0.70)$ in a nonclinical sample for the revised obsessive-compulsive inventory have been obtained [14] [15]. Convergent validity supports the OCI-R and represents a high correlation between the questionnaire and other obsessive-compulsive scales [15]. Discriminant validity also supports the OCI-R and indicates that the scale is able to discriminate OCD sufferers from other patients [16] [17]. In Iran, [18] have standardized the Persian version of OCI-R. The results showed that the OCI-R in the Iranian sample has a good validity and reliability.

2) Demography form: it's a researcher-made form which determines personal status of the patient in terms of age, gender, marital status, family members, educational status, parents' educational level, early referral to a psychiatrist or psychologist for psychological problems and history of drug use and duration of the illness.

In the present study, to compare various experimental data, the data were plotted on a graph and apparent differences of the data were considered. For each participant, the relevant data for the baseline, intervention and follow-up status were plotted on a graph, respectively. The most widely used strategy for data analysis in the single-subject research is visual analysis. In order to determine the effect of the independent variable on the dependent variable, the data collected and visually inspect the differences between phases.

Measures were taken at Baseline 1, Baseline 2, Baseline 3, Treatment 1, Treatment 2, Treatment 3, Treatment 4, and follow-up (after 1 and 2-months).

In this study to observe moral considerations, it is explained to the participants that they are going to take part in a research which aims to construct and evaluate a new treatment model on obsession symptoms. The clients were also assured that their information will be completely confidential. Moreover, along with answering to all questions of the participants about the research, they were assured that the results of the study will be published statistically as an overall conclusion and not individually and they are free to take part in the study or not and in any stage of the study they can quit the study.

\section{Results}

In this section, the obtained results from individual intervention program have been examined. To this end, the data collected from the three situations of baseline, intervention and follow-up for each participant will be plotted on a graph. Then, in order to analyze and interpret the graphs, inter-situation, intra-situation and changes in the similar circumstances of each graph were discussed. 
The results of Table 1 are presented on a graph in Figure 1.

As represented in Table 1 and Table 2 and Figure 1, the behavioral-cognitive-metacognitive intervention affected symptoms of obsessive-compulsive disorder in three participants of the study and reduced severity of the illness. As can be seen in Figure 1, scores reduction in the treatment period is significant compared to the baseline period, and this reduction has also been continued in the follow-up period, and changes in the mean level (Table 2) is also an evidence of this issue. Therefore, the results show that the developed intervention of the study has significant effects on the symptoms of OCD.

Also, the analyses showed that behavioral-cognitive-metacognitive intervention had a significant effect on reducing the symptoms of hoarding, washing, ordering, checking out, obsession and mental neutralizing symptoms in OCD patients compared with the pre-treatment and score improvement persisted at follow-up.

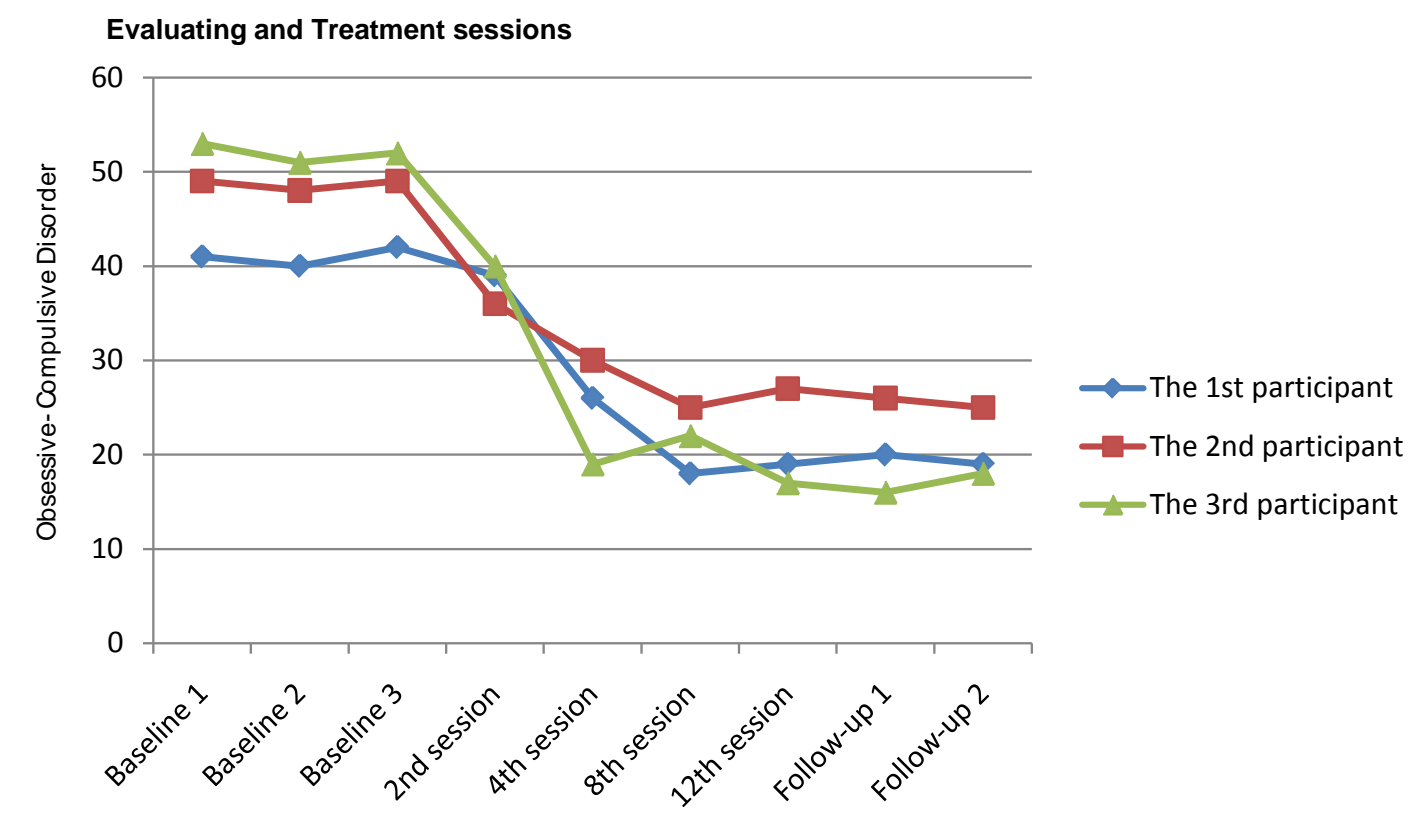

Figure 1. The effectiveness of behavioral-cognitive-metacognitive intervention on obsessive-compulsive disorder symptoms.

Table 1. The scores of the three participants in baseline, intervention and follow-up situations.

\begin{tabular}{|c|c|c|c|c|c|c|c|c|c|}
\hline \multirow{3}{*}{ Participants } & \multicolumn{9}{|c|}{ Sessions } \\
\hline & \multicolumn{3}{|c|}{ Baseline } & \multicolumn{4}{|c|}{ Treatment } & \multicolumn{2}{|c|}{ Follow-up } \\
\hline & $\begin{array}{l}\text { The } \\
\text { first }\end{array}$ & $\begin{array}{l}\text { The } \\
\text { second }\end{array}$ & $\begin{array}{l}\text { The } \\
\text { third }\end{array}$ & $\begin{array}{l}\text { The second } \\
\text { treatment } \\
\text { session }\end{array}$ & $\begin{array}{l}\text { The forth } \\
\text { treatment } \\
\text { session }\end{array}$ & $\begin{array}{l}\text { The eighth } \\
\text { treatment } \\
\text { session }\end{array}$ & $\begin{array}{c}\text { The twelfth } \\
\text { treatment } \\
\text { session }\end{array}$ & $\begin{array}{c}\text { One } \\
\text { month }\end{array}$ & $\begin{array}{l}\text { Two } \\
\text { months }\end{array}$ \\
\hline 1 & 41 & 40 & 42 & 39 & 26 & 18 & 19 & 20 & 19 \\
\hline 2 & 49 & 48 & 49 & 36 & 30 & 25 & 27 & 26 & 25 \\
\hline 3 & 53 & 51 & 52 & 40 & 19 & 22 & 17 & 16 & 18 \\
\hline
\end{tabular}

Table 2. Change in mean level, the mean difference between the positions A and B.

\begin{tabular}{cccc}
\hline Participants & The mean of the baseline, A & The mean of treatment, B & Change in mean level \\
\hline 1 & 40.66 & 25.5 & -15.16 \\
2 & 48.66 & 29.5 & -19.16 \\
3 & 52 & 24.5 & -27.5 \\
\hline
\end{tabular}


These patients were treated with behavioral-cognitive-metacognitive intervention by a single-subject method that the finding of this study was also consistent with the results of Donyavi and Rabiei et al. [12].

\section{Discussion}

The present study was conducted to evaluate the effectiveness of behavioral-cognitive-metacognitive intervention on the symptoms of OCD. In this intervention, behavioral components (avoidance, obsessive and safetyseeking behaviors) — cognitive components (core beliefs, intermediate beliefs and automatic thoughts)—metacognitive components (positive and negative metacognitive beliefs and metacognitive strategies) have been considered in OCD explanation. Regarding the relationship between cognitive components and OCD, this study is in line with [3] [5] [19]. Among the reasons for this relationship, it can be noted that in these patients, it is the more general and comprehensive underlying, inflexible, rigid, negative and irrational beliefs that cause mind's natural processes associate with cognitive distortions, leading to an increase in negative automatic thoughts in these patients. The findings of the study is also consistent with the results of [2] [3] [12] [19] regarding the relationship between behavioral components and OCD.

In general, it can be concluded that because CBT approach takes into consideration only the cognitive and behavioral aspects and ignores the metacognitive aspects such as metaworry and thought control strategies, has some deficiencies and limitations. On the other hand, metacognitive approach also has some weaknesses and limitations because it takes into consideration only the processing aspects and has less emphasis on behavioral and cognitive aspects (such as core beliefs, intermediate beliefs, cognitive distortions and negative automatic thoughts). The developed model in the present study takes into consideration all the three behavioral, cognitive and metacognitive aspects and in this model it is believed that in OCD, these three aspects are interdependent and have interaction with each other. As mentioned in the intervention, the cognitive factors such as core beliefs and negative automatic thoughts cause an increase in worry and then followed by metaworry and these factors cause an increase in the obsessive behaviors and thought control strategies. Whereas the cognitive view believes that the cognitive factors may cause the disorder by itself. [20]-[22] were among the first researchers who discovered this issue. In their study, $87 \%$ of non-clinical samples have reported that they have impulses, images, unwanted and annoying thoughts similar to those who suffer from OCD (such as repugnant feelings, dirtiness, pollution, accidents, injuries, aggression, blasphemy, sexual, etc). Further researches indicated the existence of $80 \%$ to $90 \%$ of the impulses, images, and obsessive and annoying thoughts in healthy ones [11] [20] [23].

In the developed intervention of the present study, it is believed that negative cognitions can be problematic when they cause metaworry. Metaworry occurs when one fears from his/her negative cognitions and considers them abnormal and special to his/her own mind. [24] believes that when people are afraid of their thoughts and consider them abnormal and uncontrollable, they frighten themselves more and at the same time try to eliminate and control their thoughts due to worry and fear. [25]-[27] believe that efforts to control and eliminate the negative thoughts don't cause a decrease in the negative thoughts and impulses, but cause failure in controlling thoughts, and sometimes increase the negative thoughts. When one disappoints to control the negative thoughts, $\mathrm{s} /$ he resorts to the obsessive, avoidance and safety-seeking behaviors to reduce his/her anxiety and stress [28] [29]. Obsessive and avoidance behaviors reduce the anxiety temporarily and this issue encourages individuals to use the obsessive behaviors frequently and compulsorily, but this action leads to the retention of obsessive behaviors in the long run and result in duration of the disorder. Therefore, in explanation of the OCD from the viewpoint of the developed intervention in the present study, all the three behavioral, cognitive and metacognitive aspects and their interactions have been taken into consideration.

\section{Conclusion}

All in all, it can be concluded that Behavioral-Cognitive-Metacognitive intervention is an effective treatment for OCD. Furthermore, the effect was somewhat more pronounced in Thought-Fusion symptoms than in OCD symptoms. This paper aimed to describe the aspects of the metacognitive model and treatment of OCD. It is possible that an explicit treatment focus on metacognition could improve the absolute efficacy rates for this disorder. Whilst studies evaluating the efficacy of metacognitive therapy are in their infancy, the results thus far are promising and merit further large scale investigations. A fascinating and enlightening study would be a direct comparison of Behavioral-Cognitive-Metacognitive intervention with CT, CBT and drug therapy. This would further highlight the differences and similarities between treatment approaches and their putative mechanisms of action in OCD. 


\section{Acknowledgements}

The authors would also like to acknowledge the assistance of participants and all of the clinicians and research assistants who conducted the assessments.

\section{References}

[1] Toro-Martinez, E. (2014) DSM-5: OCD and Related Disorders. Vertex, 25, 63-67.

[2] Gillan, C.M. and Sahakian, B.J. (2015) Which Is the Driver, the Obsessions or the Compulsions, in OCD? Neuropsychopharmacology Reviews, 40, 247-248. http://dx.doi.org/10.1038/npp.2014.201

[3] Purdon, C. and Clark, D.A. (1993) Obsessive Intrusive Thoughts in Nonclinical Subjects. Part I. Content and Relation with Depressive, Anxious and Obsessional Symptoms. Behaviour Research and Therapy, 31, 713-720. http://dx.doi.org/10.1016/0005-7967(93)90001-B

[4] Sulkowski, M.L., Mancil, T.L., Jordan, C., Reid, A., Chakoff, E. and Storch, E.A. (2011) Validation of a Classification System of Obsessive-Compulsive Spectrum Disorder Symptoms in a Non-Clinical Sample. Psychiatry Research, 188, 65-70. http://dx.doi.org/10.1016/j.psychres.2011.01.015

[5] Williams, M.E., Wigg, K., Zai, G., Rector, N.A. and Richter, P.M.A. (2015) Obsessive-Compulsive Disorder Symptom Presentation in OCD Patients with and without a History of Major Depression. Biological Psychiatry, 77.

[6] Rabiei, M., Khormdel, K., Kalantari, K. and Molavi, H. (2010) Validity of the Yale-Brown Obsessive Compulsive Scale Modified for Body Dysmorphic Disorder (BDD) in Students of the University of Isfahan. Iranian Journal of Psychiatry and Clinical Psychology, 15, 343-350.

[7] Rabiei, M., Mulkens, S., Kalantari, M., Molavi, H. and Bahrami, F. (2012) Metacognitive Therapy for Body Dysmorphic Disorder Patients in Iran: Acceptability and Proof of Concept. Journal of Behavior Therapy and Experimental Psychiatry, 43, 724-729. http://dx.doi.org/10.1016/j.jbtep.2011.09.013

[8] Rabiei, M., Salahian, A., Bahrami, F. and Palahang, H. (2011) Construction and Standardization of the Body Dysmorphic Metacognition Questionnaire. Journal of Mazandaran University of Medical Sciences, 21, 43-52.

[9] Rabiei, M. (2014) The Effectiveness of Metacognitive-Cognitive-Behavioral Intervention on Severity of the Symptoms of Hair Pulling Disorder. Journal of Behavioral Sciences, 7, 21-22.

[10] Rabiei, M., Donyavi, V., Nikfarjam, M. and Mohammad Nezhady, M.A. (2015) Validation of a Classification System for Obsessive-Compulsive and Related Disorders Based on DSM-5. Open Journal of Psychiatry, 5, 137-143. http://dx.doi.org/10.4236/ojpsych.2015.52015

[11] Donyavi, V., Rabiei, M., Nikfarjam, M. and Nezhady, B.M. (2015) Body Image and Meta-Worry as Mediators of Body Dysmorphic Disorder. International Journal of Clinical Medicine, 6, 170-176.

http://dx.doi.org/10.4236/ijcm.2015.63022

[12] Donyavi, V., Rabiei, M., Nikfarjam, M. and Rahnejat, A.M. (2015) Develop and Validate a Metacognitive-CognitiveBehavioral Model for Body Dysmorphic Disorder. Open Journal of Medical Psychology, 4, 45-52. http://dx.doi.org/10.4236/ojmp.2015.42005

[13] Foa, E.B., Huppert, J.D., Leiberg, S., Langner, R., Kichic, R., Hajcak, G., et al. (2002) The Obsessive-Compulsive Inventory: Development and Validation of a Short Version. Psychological Assessment, 14, 485-496. http://dx.doi.org/10.1037/1040-3590.14.4.485

[14] Gonner, S., Leonhart, R. and Ecker, W. (2008) The Obsessive-Compulsive Inventory-Revised (OCI-R): Validation of the German Version in a Sample of Patients with OCD, Anxiety Disorders, and Depressive Disorders. Journal of Anxiety Disorders, 22, 734-749. http://dx.doi.org/10.1016/j.janxdis.2007.07.007

[15] Jones, A.M., De Nadai, A.S., Arnold, E.B., McGuire, J.F., Lewin, A.B., Murphy, T.K., et al. (2013) Psychometric Properties of the Obsessive Compulsive Inventory: Child Version in Children and Adolescents with Obsessive-Compulsive Disorder. Child Psychiatry and Human Development, 44, 137-151. http://dx.doi.org/10.1007/s10578-012-0315-0

[16] Abramowitz, J.S. and Deacon, B.J. (2006) Psychometric Properties and Construct Validity of the Obsessive-Compulsive Inventory-Revised: Replication and Extension with a Clinical Sample. Journal of Anxiety Disorders, 20, 1016-1035. http://dx.doi.org/10.1016/j.janxdis.2006.03.001

[17] Foa, E.B., Coles, M., Huppert, J.D., Pasupuleti, R.V., Franklin, M.E. and March, J. (2010) Development and Validation of a Child Version of the Obsessive Compulsive Inventory. Behavior Therapy, 41, 121-132. http://dx.doi.org/10.1016/j.beth.2009.02.001

[18] Ghassemzadeh, H., Mojtabai, R., Karamghadiri, N. and Ebrahimkhani, N. (2005) Psychometric Properties of a Persian-Language Version of the Beck Depression Inventory-Second Edition: BDI-II-PERSIAN. Depression and Anxiety, 21, 185-192. http://dx.doi.org/10.1002/da.20070 
[19] Freeston, M.H., Ladouceur, R., Gagnon, F., Thibodeau, N., Rheaume, J., Letarte, H., et al. (1997) Cognitive-Behavioral Treatment of Obsessive Thoughts: A Controlled Study. Journal of Consulting and Clinical Psychology, 65, 405-413. http://dx.doi.org/10.1037/0022-006X.65.3.405

[20] Rachman, S. (2007) Unwanted Intrusive Images in Obsessive Compulsive Disorders. Journal of Behavior Therapy and Experimental Psychiatry, 38, 402-410. http://dx.doi.org/10.1016/j.jbtep.2007.10.008

[21] Rachman, S., Hodgson, R. and Marks, I.M. (1971) The Treatment of Chronic Obsessive-Compulsive Neurosis. Behaviour Research and Therapy, 9, 237-247. http://dx.doi.org/10.1016/0005-7967(71)90009-X

[22] Shafran, R., Radomsky, A.S., Coughtrey, A.E. and Rachman, S. (2013) Advances in the Cognitive Behavioural Treatment of Obsessive Compulsive Disorder. Cognitive Behaviour Therapy, 42, 265-274. http://dx.doi.org/10.1080/16506073.2013.773061

[23] Coughtrey, A.E., Shafran, R., Lee, M. and Rachman, S.J. (2012) It’s the Feeling Inside My Head: A Qualitative Analysis of Mental Contamination in Obsessive-Compulsive Disorder. Behavioural and Cognitive Psychotherapy, 40, 163173. http://dx.doi.org/10.1017/S1352465811000658

[24] Wells, A. (2009) Metacognitive Therapy for Anxiety and Depression. Guilford Press, New York, 316 p.

[25] Wells, A. and Papageorgiou, C. (1998) Relationships between Worry, Obsessive-Compulsive Symptoms and MetaCognitive Beliefs. Behaviour Research and Therapy, 36, 899-913. http://dx.doi.org/10.1016/S0005-7967(98)00070-9

[26] Wells, M.C., Glickaufhughes, C. and Buzzell, V. (1990) Treating Obsessive-Compulsive Personalities in Psychodynamic Interpersonal Group-Therapy. Psychotherapy Theory Research \& Practice, 27, 366-379.

[27] Fisher, P.L. and Wells, A. (2008) Metacognitive Therapy for Obsessive-Compulsive Disorder: A Case Series. Journal of Behavior Therapy and Experimental Psychiatry, 39, 117-132. http://dx.doi.org/10.1016/j.jbtep.2006.12.001

[28] Solem, S., Myers, S.G., Fisher, P.L., Vogel, P.A. and Wells, A. (2010) An Empirical Test of the Metacognitive Model of Obsessive-Compulsive Symptoms: Replication and Extension. Journal of Anxiety Disorders, 24, 79-86. http://dx.doi.org/10.1016/j.janxdis.2009.08.009

[29] Solem, S., Haland, A.T., Vogel, P.A., Hansen, B. and Wells, A. (2009) Change in Metacognitions Predicts Outcome in Obsessive-Compulsive Disorder Patients Undergoing Treatment with Exposure and Response Prevention. Behaviour Research and Therapy, 47, 301-307. http://dx.doi.org/10.1016/j.brat.2009.01.003 